\title{
Ostracismo organizacional: núcleos conceptuales para la comprensión del fenómeno
}

\author{
Estévez, Alejandro M.* \\ Serlin, José **
}

\section{Resumen}

El ser excluido, rechazado, aislado por parte de un grupo social, no es un fenómeno nuevo en las organizaciones. El exilio u ostracismo es una forma de violencia que se aplica sobre un individuo a los efectos de disciplinarlo o expulsarlo de un cierto grupo de pertenencia. En las organizaciones modernas la práctica del exilio tiene efectos sobre el individuo y sobre la cohesión del grupo que aplica el castigo. El artículo tiene por objetivo revisar el fenómeno del exilio u ostracismo organizacional para mostrar su evolución histórica y tener una mejor comprensión de la problemática. El método empleado es de tipo cualitativo y está basado en el análisis bibliográfico y documental. Las conclusiones muestran la evolución del ostracismo y sus desaconsejables intentos de aplicación práctica en las organizaciones.

Palabras clave: Ostracismo organizacional, exilio organizacional, incomunicación, rechazo organizacional, tratamiento silencioso.

Recibido: 21-01-13. Aceptado: 30-06-13

* Ph.D. en Administración Pública de la Université du Québec, Canadá. Es profesor de Administración Pública en la Universidad de Buenos Aires y de Políticas Públicas en la Universidad Torcuato Di Tella. Es profesor invitado en el IEP (Institut d'études politiques) Université Pierre Mendes-France, Grenoble; es Director de la ONG Polipub.org (e-mail: aestevez@polipub.org).

** Doctor de la Universidad de Buenos Aires. Profesor consulto titular de la Facultad de Ciencias Económicas de la Universidad de Buenos Aires. Profesor de "Comunicación Organizacional" en la FCE-UBA. Es Subdirector del Centro de Investigaciones en Administración Pública, FCE-UBA. Ha sido consultor de organismos internacionales (e-mail: serlin@arnet.com.ar). 


\title{
Organizational Ostracism: Conceptual Nuclei for Understanding the Phenomenon
}

\begin{abstract}
Being excluded, rejected, isolated by a social group is not a new phenomenon in organizations. Exile or ostracism is form of violence applied to an individual for disciplinary reasons or to expel him or her from a certain group of belonging. In modern organizations, the practice of exile has effects on the individual and on the cohesion of the group that applies the punishment. The objective of this article is to review the phenomenon of exile or organizational ostracism to show its historical evolution and obtain a better understanding of the problem. The method used is of the qualitative type based on bibliographic and documentary analysis. Conclusions show the evolution of ostracism and its unadvisable attempts at practical application in organizations.
\end{abstract}

Keywords: organizational ostracism, organizational exile, non-communication, organizational rejection, silent treatment.

\section{Introducción}

En las organizaciones modernas, hay personas que sufren de aislamiento. Sus compañeros que antes lo reconocían, a partir de un determinado momento comienzan a ignorarlos, a castigarlos con la invisibilidad y la falta de comunicación. También se registran casos de personas que trabajando cotidianamente en una organización, nunca pudieron ser aceptados como miembros plenos, aunque le hayan dedicado ingentes esfuerzos para serlo. Este "tratamiento silencioso" puede tener diversas causas, pero el objetivo del mismo es ejercer un castigo por una cierta transgresión de un individuo o grupo de individuos a los valores, códigos, reglas, tradiciones o usos dominantes en una organización (Baumeister, Twenge y Nuss, 2002; Macdonald y Leary, 2005).

Por otro lado, en las organizaciones, hay lugares en los cuales -tanto físi- cos como simbólicos- "se confina" a los exiliados como una forma de hacerlos pagar por la culpa que se les imputa. No se hace referencia aquí a las transgresiones menores que son "sancionadas" por un grupo dominante en la organización, sino que se busca comprender a aquellos castigos que se le aplican a personas que por sus visiones, opiniones, acciones, liderazgo $o$ actitudes personales son percibidos como una amenaza y puestos bajo un manto de "silencio organizacional" (Williams, 2001).

¿Por qué se debe estudiar el ostracismo organizacional? la razón es muy sencilla, en el mundo moderno se registran diversas formas de violencia en las organizaciones. Hay individuos que son acosados laboralmente y sobre los cuales un grupo de la organización ejerce un alto nivel de violencia tanto simbólica como física que afectan profundamente el equilibrio psíquico y la performance de la víctima (Williams, 2007a, 2007 b). Los 
periódicos ${ }^{1}$, publican casos de personas que se suicidan con motivo de reformas organizacionales por las cuales se puso en cuestión su habilidad profesional, su sentido de pertenencia, su sentido de utilidad y su autoestima (El mundo, 2012).

También se observa que dos tercios de los tiradores seriales que se registran en Estados Unidos han sufrido en algún momento largos "exilios" organizacionales -reales o percibidos- contra los cuales reaccionan con violencia inusitada. Existe también el caso de individuos que se enrolaron en organizaciones terroristas o mafiosas porque sienten que han sido "exiliados" por la sociedad más grande en la que habitaban (Williams, 2007a, 2007 b).

Las organizaciones modernas están sufriendo uno de los más profundos cambios que registran en su historia, a raíz de la globalización y la revolución tecnológica. Las relaciones entre los distintos actores, la estabilidad de ciertas reglas de juego, las cambiantes condiciones del mercado, el debilitamiento de ciertos paradigmas tradicionales de pensamiento, el incremento de las desigualdades sociales, el dinamismo de las opiniones públicas y la demanda por una mayor democratización en la sociedad, llevan a que la cuestión del "exilio organizacional" sea un tópico que está cobrando una mayor relevancia en la teoría organizacional moderna. Por ello es pertinente estudiar este tipo de exilio como una forma de comprender el efecto de los cambios en las organizaciones. Pero se debe reconocer que el exilio, no es un fenómeno nuevo, sino que la mirada con la cual se aborda el problema le otorga una visibilidad distinta a la que tenía anteriormente (Schechtman, 2008; Zadro et al., 2004; Williams, 2001).

En atención a lo antes planteado, el objeto de este artículo es revisar el fenómeno del ostracismo organizacional para mostrar su evolución histórica y tener una mejor comprensión de la problemática. Desde el punto de vista metodológico, se empleó el análisis de tipo bibliográfico y documental, siguiendo los estándares fijados por Yin (1994), Creswell (1998), Stake (2010) y Robson (2002) para la investigación de tipo cualitativa.

El relevamiento del "estado del arte", ya sea a través de libros o documentos especializados, es un prerrequisito para la búsqueda de un mayor nivel de precisión conceptual en la comprensión de un fenómeno. En el marco de esta búsqueda, se ha privilegiado la información que aportará tipologías, procesos y casos de ostracismo organizacional. No se ha encontrado una "revisión de la bibliografía" como las que existen de otras temáticas, por lo cual, se construyó un relevamiento propio, que es en buena parte este artículo. En cuanto a la fuente de los documentos han sido bases de datos digitales e internet, además de libros e informes disponibles.

1 En el caso de France Telecom, se registraron cerca de 25 suicidios que se dieron en un contexto de reforma organizacional, al haber despedido entre 2008 y 2011 a 22.000 empleados. Su gerente, Didier Lombard termina siendo procesado por la justicia francesa ante las reiteradas denuncias del gremio por "acoso laboral" y "poner en peligro la vida de otros". 


\section{El ostracismo como concepto}

Se entiende por ostracismo a cualquier comportamiento, real o percibido, mediante el cual un grupo social aísla, ignora, rechaza o excluye a un individuo bajo el argumento de una transgresión, omisión, amenaza u ofensa grave a los valores, cultura, códigos, usos o costumbres de una organización. El término ostracismo data del Siglo $V$ antes de Cristo y emergió en la antigua Grecia, cuando fue usado para proteger al poder en la democracia ateniense (Kagan, 1961; Lustenberg y Williams, 2008).

Ciertas especies animales tienden a aplicar el ostracismo como una forma de castigo a aquellos individuos que osaron desafiar el poder del macho dominante, tal es el caso que se observa en los leones. Por lo general, el león que es exiliado muere por inanición al privárselo de la ceremonia de la cacería en la cual se alimentan grupalmente (Williams, 2007a; Gruter y Masters, 1986).

El ostracismo incluye otras situaciones además de la falta de comunicación verbal. Someter a una persona al "tratamiento silencioso" puede incluir el fingir que ese ser humano es absoluta y completamente invisible. También incluye el rechazar a una persona enviándola a otra parte o en forma encubierta evitar su presencia física en la organización. Diversas investigaciones experimentales han demostrado que la reacción al ostracismo puede incluir desde actos de agresión y resignación depresiva hasta conformidad social y comportamientos pro sociales (Longzeng et al., 2011; Williams, 2001, 2007a, 2007 b).
Desde un punto de vista evolutivo, el ostracismo puede haber tenido una función adaptativa: eliminar individuos desviados o liderazgos disfuncionales, permitiendo a los sobrevivientes tener una mayor cohesión y mejores posibilidades de reproducción. Deben ser mencionados algunos aspectos interesantes del ostracismo como comportamiento social (Williams, 2001, 2007b; Lustenberg y Williams, 2008; Gruter y Masters, 1986; Baumeister et al., 2002; Macdonald y Leary, 2005):

a. El ostracismo es la falta de atención y comunicación directa hacia otra persona o grupo. En consecuencia, desde una perspectiva de tercera persona, no siempre es directamente observable ni sobresale a los sentidos de terceros. Esto causa la inimputabilidad de una agresión, dado que la deja sin testigos.

b. Los actos de ostracismo pueden ser bastante ambiguos. Esto provoca dudas en el receptor de la agresión acerca de si un acto fue de ostracismo o no. Es difícil resolver esta ambigüedad. Es improbable que genere una respuesta satisfactoria y no permite preguntar al agresor acerca de la intencionalidad del acto. En consecuencia, el ostracismo puede ser una experiencia confusa y desorientadora.

c. El ostracismo puede tener cualquier extensión de tiempo, desde durar unos minutos, a toda la vida. La duración y/o cronicidad del ostracismo puede determinar la forma en que la gente reacciona al evento.

d. Los efectos del ostracismo pueden ser tanto debilitantes como adaptativos. Como ya se dijo, puede amenazar los 
sentimientos de una persona en los dominios de pertenencia a un grupo, sentido de control, autoestima y del sentido de su existencia. O ajustarse a las normas del grupo, adaptarse a vivir en él y aprender cómo hacerlo.

e. Se lo conoce como el "tratamiento silencioso" porque a la víctima no se le habla, se la aísla, se la somete a condiciones de invisibilidad y de rechazo.

Ahora bien, con la aparición de la revolución tecnológica en las comunicaciones y a través de internet y las redes virtuales o sociales, el ostracismo como actividad sumó una nueva variedad o forma para su ejercicio, mediatizado por los recursos electrónicos y conocido como "ciberostracismo" (Schechtman, 2008; Williams, 2007 a, 2007 b; Van Beest y Williams, 2006).

La tecnología ha permitido una mayor comunicación en el ambiente laboral y posibilitó formar redes o grupo virtuales que han extendido el alcance de los equipos de trabajo. Hay grupos que funcionan con sus integrantes a miles de kilómetros de distancia y esto no baja la performance. Hay diarios que se escriben sin que los periodistas tengan que compartir siquiera el ámbito de trabajo; hay diseños de arquitectura o productos industriales que se hacen en distintas partes del mundo a través de una red; existen redes solidarias bien coordinadas en las cuales sus miembros están esparcidos en varios continentes. En el mundo educativo, los cursos virtuales ya están ampliamente difundidos. Los equipos de trabajo ya no necesitan compartir un ambiente físico común. La comunicación está mediada por la computadora, fenómeno cuyas siglas son CMC (Schechtman, 2008).
En un equipo de trabajo virtual es absolutamente necesario el intercambio frecuente de correos electrónicos, mensajes de texto, mensajería instantánea, teleconferencias, llamadas telefónicas, etc. El ciberostracismo como fenómeno ligado a la tecnología o a las CMC, implica que un miembro de ese grupo virtual es "incomunicado" o aislado por el resto del equipo. Puede ocurrir de una forma directa y advertida al "exiliado" o incremental; poco a poco dejará de recibir fluidamente comunicaciones del resto de los miembros de la red o el tono de comunicación y la capacidad de acceso que usualmente se le brindaban se van "enfriando" (Schechtman, 2008; Williams, 2007 a, 2007 b; Van Beest y Williams, 2006; Serlin, 2000).

Los efectos del ciberostracismo son iguales que los de ostracismo ordinario que tratamos en este artículo y sus efectos se sienten más rápido. Según Williams (2007 a, 2007 b) en sólo cinco minutos de simulación de ostracismo en un experimento, sus víctimas percibieron su situación de "tratamiento silencioso". También la investigación de Zadro et al. (2004) demuestra con sus experimentos realizados mediante simulación computarizada, que las víctimas sufren idénticas variaciones en las mismas variables que el ostracismo común (sentido de pertenencia, sentido de control de su medio social, sentido de su existencia y autoestima).

Schechtman (2008) ha realizado una profunda investigación sobre el ciberostracismo. Sostiene que ya no se necesita cierta proximidad de la víctima para aplicarle "el tratamiento silencioso". Así como las redes virtuales extendieron las comunicaciones de los grupos de trabajo 
e incrementaron la velocidad de sus intercambios, también ampliaron el alcance del ostracismo. El ciberacoso es un fenómeno asociado al ciberostracismo pero no está dentro de nuestro objeto de estudio en este artículo.

\section{Evolución histórica del ostracismo}

Una vez clarificados los límites del ostracismo como concepto, se procede al abordaje de su evolución histórica.

\subsection{El ostracismo en la Grecia Clásica}

Es una forma de castigo que tiene 2.500 años de vigencia. Fue establecida en Atenas, en el año 510 a.c. por Clístenes quien fuera un político griego que introdujo una serie de reformas sociales e institucionales cuya implementación posibilitó ciertos desarrollos democráticos posteriores $^{2}$. El ostracismo tenía como propósito original combatir a los liderazgos fuertes que pudieran derivar en tiranías. Poseía una finalidad cívica y luego comienza a ser utilizado como un instrumento mediante el cual las distintas facciones contendían exiliando a personajes claves o líderes de sus grupos rivales (Kagan, 1961).
Para aplicarlo, cada año se reunía en Atenas la asamblea del pueblo; sufragaban a mano alzada y si el resultado era positivo, convocaban a una nueva votación pública dos meses más tarde. Esta elección se hacía al pie de la colina en la que se ubicaba el Cerámico, el barrio del gremio alfarero de Atenas. Al pie de dicha colina se arrojaban los productos de alfarería defectuosos, rompiéndose en trozos que recordaban la forma cóncava e irregular de una concha de ostra (ostracon). En esta votación cada votante escribía el nombre de la persona a quien quería desterrar (Kitto, 1977).

La medida consistía en desterrar por diez años a cualquier ciudadano que el pueblo considerara -por sufragio- peligroso para el mantenimiento del orden público de la polis. Todos los años podía apelarse a esta medida, era un simple recurso político. Concluidos los diez años, el desterrado volvía a su patria (polis) y entraba en el goce de todos sus derechos ciudadanos (Kagan, 1961; Kitto 1977).

Un caso que frecuentemente se menciona ligado al ostracismo, es el de Sócrates (470 a 399 a. C.), quien fuera condenado por la asamblea ateniense y conminado a elegir entre el ostracismo o la muerte por ingesta de "cicuta" (optó por esta última). El filósofo sufrió la desconfianza de muchos de sus contemporá-

Clístenes, estructuró una nueva polis basada en la "isonomía" o igualdad ante la ley. Rompe las antiguas alianzas de familias, crea las tribus territoriales, reorganiza el ejército, crea el Consejo de los quinientos -Boulé- y establece el ostracismo para proteger a la naciente democracia en contra de las ambiciones personales de ciertos políticos. En la mayoría de las polis dominaba la oligarquía, de manera que Atenas era una especie de excepción. Cada polis era autónoma. Las unía una cultura común expresada sobre todo en cierto espíritu cívico y lo religioso. El oráculo de Delfos tenía en este sentido un papel importa (Kagan, 1961; Kitto, 1977). 
neos por sus enseñanzas basadas en la ironía socrática, a los que les disgustaba la postura que tomó frente al Estado ateniense, sus dirigentes y la religión establecida, principalmente por las creencias metafísicas de Sócrates, que planteaban una existencia etérea sin el consentimiento de ningún dios como figura explícita. Es decir, desafió tanto a los grupos de dirigentes políticos como a la "religión establecida". Su continua búsqueda de la sabiduría, asumiéndose como ignorante mediante la duda socrática ("sólo sé que no sé nada") y su comportamiento austero y ejemplar, más la premisa auto liberadora "conócete a ti mismo", fueron generándole enemigos en ciertos sectores dirigentes que terminan en su condena. Fue acusado en el 399 a. c. de despreciar a los dioses y corromper la moral de la juventud, alejándola de los principios de la democracia (Kagan, 1961; Platon, 2007).

\subsection{El ostracismo con el helenismo}

Es Alejandro Magno (356-323) quien con la expansión de su imperio helenístico, lleva la institución del ostracismo a distintas culturas, entre ellas al judaísmo, quienes lo aplican al ámbito religioso mientras que para las tradiciones griegas era un instrumento preponderantemente cívico. Al comienzo de las conquistas de Alejandro en 334, la región de Judea vivía sin sobresaltos bajo el dominio persa. En Palestina se fundaron más de 30 polis. Los pobladores de las nuevas polis, mayormente macedonios y griegos, hicieron de Medio Oriente una palestra de la cultura griega y de los tipos de vida griego (Eban, 1968).
En Alejandría (Egipto) se produjo la convergencia de los espíritus hebreos y griegos. Los judíos de Alejandría produjeron una cultura original sellada por la fusión de ambas tradiciones, que influyó sobre la filosofía del mundo antiguo y sobre el cristianismo primitivo. En esta fusión hebrea-helenística transmitida luego al cristianismo, se introdujo la institución del ostracismo (Kagan, 1961; Eliade, 1961).

\subsection{El ostracismo en la tradición judeo-cristiana}

En tiempos de Cristo, el ostracismo era una pena reconocida entre los hebreos. En la Mishná (compilación de la ley bíblica judía) se distingue entre dos grados; el menos riguroso (Niddui) implicaba para un transgresor la exclusión de la vida en la comunidad durante un periodo de 7 a 30 días, con la obligación de cumplir penitencia y vestirse de luto. La condena más dura (Jerem) es más formal e implica un solemne ritual de anatematismo indefinido. En la tradición hebrea, no se puede excomulgar a un individuo (ser excluido de recibir la comunión y los sacramentos) porque estos no existen en la religión judía (Eban, 1968).

A diferencia de la iglesia católica, no existe en el judaísmo una autoridad suprema reconocida ni una organización vertical que permita emitir una determinación universalmente válida, $y$, en la ley y en los hechos, un judío (nativo o converso) no deja de ser judío hasta que se muere. Por ello, no hay excomunión sino excomunicación, se lo "quita" de la comunicación a alguien. Hay casos famosos 
en la religión hebrea, tales como la del filósofo Baruch Espinoza, el texto de su condena es explícito: "Ordenamos que nadie mantenga con él comunicación oral o escrita, que nadie le preste ningún favor, que nadie permanezca con él bajo el mismo techo o a menos de cuatro yardas, que nadie lea nada escrito o transcripto por él" (Eban, 1968).

Desde los comienzos de la Iglesia cristiana, ésta reconoció una pena similar, llamada excomunión. Se establecieron dos grados de excomunión: una mayor y otra menor; la menor implicaba la exclusión del sacramento de la eucaristía y de los privilegios de la Iglesia. La mayor se aplicaba a los pecadores obstinados, los apóstatas perseverantes y los herejes; su forma era más solemne y era muy difícil de revocar. La duración de la excomunión era decidida por el obispo. En África y en España, la absolución de los individuos laicos que en tiempos de persecución se habían alejado de su fe cristiana y adorado a ídolos paganos estaba prohibida, excepto en el momento de la muerte (Eliade, 1961; De La Garza y Valdés, 1998).

Conforme los gobiernos abrazaron el cristianismo como religión de carácter oficial, la excomunión mayor conllevó la pérdida de los derechos políticos y la exclusión de funciones públicas. El ostracis- mo, como instrumento de castigo de ciertos grupos religiosos, poco a poco se va instituyendo en el orden político. Las capitulares del siglo VIII, u ordenanzas de Pipino el Breve, rey de los francos, ordenaban que la excomunión mayor tuviera que ir seguida de destierro. La excomunión aplicada a los gobernantes les privaba de sus derechos para gobernar y por lo tanto liberaba a sus súbditos de vasallaje (reduciéndole los ingresos económicos al castigado); la Iglesia se convirtió así en un importante poder temporal ${ }^{3}$ (Eliade, 1961).

Los líderes de la Reforma protestante también reclamaron el poder de la excomunión para sus iglesias. Martín Lutero $^{4}$ (1483-1546) insistió en el derecho inherente de los ministros de la Iglesia para su aplicación. Martín Lutero fue excomulgado por la Iglesia Católica.

Los calvinistas por su lado, siguiendo el pensamiento del reformador francés Juan Calvino, mantenían la institución de le excomunión como una forma disciplinaria hacia el interior de su congregación y en las comunidades en las que eran mayoría.

Hasta el año 1813 en Inglaterra, las personas que habían sido excomulgadas tenían prohibido realizar acciones legales en los tribunales, ser jurado o testigo en cualquier procedimiento legal y ejercer como abogado en los tribunales de justi-

3 El texto oficial de la excomunión es "Excomulgamos y anatematizamos a ese malhechor que se hace llamar (aquí el nombre de la persona excomulgada) y le arrojamos del seno de la Santa Iglesia de Dios" (De La Garza y Valdés, 1998; Eliade, 1961).

4 Teólogo, fraile católico agustino y reformador religioso alemán. Inauguró la doctrina teológica y cultural denominada luteranismo e influyó en las demás tradiciones protestantes. Fue el principal artífice de la Reforma Protestante. 
cia del reino. De esta forma se observa cómo un castigo religioso tiene implicancias en el mundo "civil" (Eliade, 1961; De La Garza y Valdés, 1998).

La Iglesia ortodoxa cristiana, en sus distintas variantes también ha conservado la institución de la excomunión. Como los grupos cristianos amish quienes tienen una variante que se denomina meidung o rechazo social mediante la cual se aísla por completo al individuo que desafía las normas de la comunidad. Este tipo de castigo en sociedades pequeñas y cerradas al mundo exterior tiene un impacto muy fuerte en las víctimas (Eliade, 1961; De La Garza y Valdés, 1998).

\section{4. ¿Qué se entiende por ostracismo organizacional?}

Se entiende por ostracismo organizacional al fenómeno que implica que una persona es sometida por parte de un grupo social a una situación de aislamiento, rechazo, incomunicación, anatematización, no reconocimiento, con el objeto de castigar una transgresión a los valores, criterios, reglas, creencias, usos o costumbres de la organización o de un grupo dominante de la misma. No se incluye en este caso a los transgresores delictuales $u$ ordinarios que existen en todas las sociedades sino los casos que son percibidos como "amenazas" o inaceptables para un grupo o una organización social. El "ostraquizado" es sometido al "tratamiento silencioso", a la invisibilidad, a la falta de comunicación, de interacción, con el objeto de aplicarle un castigo o correctivo, para reducir su influencia o directamente eliminarlo de una co- munidad social (Schechtman, 2008; Longzeng et al, 2011; Williams, 2001, 2007 a, 2007 b; Zimmerle, 2012).

El ostracismo organizacional puede ser comprendido como una variante del castigo pero también como una forma de intimidación (Foucault, 1976). Con respecto al grado de violencia utilizado, es posible distinguirlo de otras formas vigentes de agresión social como el acoso moral, laboral, profesional o educativo (bullying y mobbing) (Aglamisis, 2011; Schechtman, 2008; Forgas et al, 2005; Van Beest y Williams, 2006).

En relación al mobbing, en la literatura vigente al respecto, se lo identifica con la noción de acoso laboral o moral, por el cual un individuo es atacado por un grupo en su lugar de trabajo buscando su humillación, intimidación, quiebre emocional, desacreditación, difamación, aislamiento, incomodidad para forzar su salida de la organización o neutralizar su influencia. Es un tipo de persecución que implica una elevada cantidad de violencia psicológica y simbólica que en algunos casos, puede desbordar en agresiones físicas (Aglamisis, 2011; Davenport et al., 2005; Hecker, 2007; Westhues, 2003; Piñuel, 2008; Fassio, 2011; Forgas et al., 2005).

En otro sentido, la noción de bullying es otra forma de violencia o de agresión social en las organizaciones que implica el acoso por parte de un grupo hacia un individuo mediante coerción física, violencia emocional, aislamiento e intimidación que generalmente se basa en excusas raciales, de género, sexualidad o habilidades distintivas. Lamentablemente, es una forma relativamente usual en el mundo de la educación entre los alumnos quienes toman como objetivo a una per- 
sona determinada a los efectos de incomodarla, forzar su salida o ejercer un poder grupal sobre la víctima. La mayoría de los casos de bullying muestran un frecuente ejercicio de la violencia física contra el damnificado (Whitted y Dupper, 2005; Einarsen et al., 2003; Crothers y Levinson, 2004; Forgas et al., 2005).

Con base en lo expuesto se puede afirmar entonces, que el ostracismo organizacional es una situación de castigo o agresión social que implica el aislamiento de la víctima. El mobbing o acoso laboral como también el bullying, van más allá, porque implican un nivel de violencia mayor (se llega a la agresión física) e inclusive el activismo grupal y la militancia en contra de la víctima es mayor. Además, la bibliografía señala que el aislamiento, ostracismo o tratamiento silencioso puede ser un instrumento en el acoso moral y buIlying (Forgas et al., 2005). El ostracismo, mobbing y bullying están presentes en las organizaciones como una forma de violencia ligada a los comportamientos sociales donde interactúan factores individuales y colectivos. Las causas de estos fenómenos pueden ser muy variadas y requieren una mayor investigación aplicada.

\section{El ostracismo y las distintas culturas}

Si bien el ostracismo o exilio organizacional es un tema que necesita una mayor profundización de tipo analítica, se puede señalar que en aquellas culturas que tienen un sesgo individualista como las occidentales, tienden a darle al ostracismo un impacto menor que las orientales, en donde consideran que el individuo se realiza o se construye dentro del grupo social. Por lo tanto, una persona sometida a ostracismo en una cultura de tipo oriental, tiene un valor simbólico más profundo aún (Longzeng et al., 2011; Forgas et al., 2005; Van Beest y Williams, 2006).

La evidencia empírica señalaría que en culturas con sesgos colectivistas, las personas que son sometidas a ostracismo presentarían cierta tendencia a la introversión, cierto desvío de una noción colectiva de "agradabilidad" o comportamientos neuróticos rechazados por el conjunto. El desafiar al grupo o desviarse del comportamiento "normal" tiene un valor transgresor más profundo que para una cultura individualista (Longzeng et al., 2011; Forgas et al., 2005; Van Beest y Williams, 2006).

El concepto de "agradabilidad" es una idea que está muy ligada al contexto cultural y estético dominante en una organización o al criterio intersubjetivo de los grupos sociales (Lederman, 2012). Según Longzeng et al. (2011) una transgresión por parte de un individuo a la noción de agradabilidad en una cultura de tipo colectivista tiene un impacto más profundo que para los contextos más individualistas de occidente. El ser catalogado de "desagradable" es una causa para ser exiliado por el conjunto. De todas formas, tanto en contextos individualistas como colectivistas, las consecuencias de los exilios tienen efectos físicos y psíquicos sobre los individuos (Lustenberg y WiIliams, 2008; Williams, 2007a, 2007 b; Van Beest y Williams, 2006).

Pero en las culturas con sesgo "individualista" como son las occidentales, Williams (2001, 2007 a, 2007 b) reconoce que $2 / 3$ de los individuos admiten haber sufrido o ejercido ostracismo o "trata- 
miento silencioso" a algún miembro de su grupo de trabajo o a un familiar en su vida privada. Con esto se quiere señalar que el ostracismo, si bien adquiere actualmente una mayor relevancia, no es un fenómeno nuevo. Schechtman (2008), afirma que con la mayor tecnologización de las comunicaciones entre los seres humanos, el ostracismo sumó una nueva forma de ejercicio y que es justamente el ciberostracismo, para el cual, el requisito de cierta proximidad con la víctima dejó de ser indispendable.

\section{Una tipología de ostracismo}

De acuerdo con lo expuesto hasta ahora, el ostracismo se registra en todos los niveles posibles del análisis organizacional. Las instituciones, las organizaciones, los grupos y la subjetividad del individuo, muestran evidencias claras a través de las cuales se puede estudiar el fenómeno (Forgas et al., 2005; Lustenberg y Williams, 2008; Williams, 2007 a, 2007 b; Schechtman, 2008).

Se intentará construir una tipología del ostracismo, desde el punto de vista de quienes lo sufren o son sus víctimas. En la bibliografía analizada, se registran básicamente tres grandes tipos, que pueden reconocer distintas situaciones intermedias y que un caso puede desplazarse fácilmente al otro. Se identifican entonces tres grandes núcleos; a saber (Williams, 2001, 2007 a, 2007 b; Van Beest y WiIliams, 2006; Lustenberg y Williams, 2008; Longzeng et al., 2011):

a. Los que perdieron en el juego político en una institución: En este caso, se encuentran individuos que representan valores, visiones, teorías, ideas o intereses que un grupo dominante en la organización percibió como amenazantes o no deseables. También puede ocurrir que este individuo haya perdido un conflicto político en la organización y que tenga una capacidad de liderazgo remanente que el grupo dominante desea neutralizar. Por dicha razón, es sometido a un exilio organizacional como una forma de aislamiento y reducción de "peligrosidad" para la cohesión general y el poder del grupo dominante en la institución. En este caso se observa también que los grupos utilizan al ostracismo como una forma de demostrar su poder a otros sectores de la organización o institución.

b. Los que sufren ostracismo inducido por el tipo de tarea o trabajo organizacional que realizan: existen ciertas condiciones laborarles que terminan induciendo al ostracismo por la naturaleza técnica de la actividad. Cada vez más, por la influencia del componente tecnológico en las organizaciones modernas, se generan trabajos "solitarios" en los cuales la persona tiene que estar controlando pantallas, sistemas y procesos que no requieren de la interacción con otros individuos. Estos trabajadores comienzan lentamente a incorporar actitudes de ostracismo y de inhibición social (social avoidance). Son las tareas y sus características de aislamiento social las que progresivamente van formando comportamientos favorables al ostracismo para aquellos individuos que se fueron adaptando a esas condiciones particulares. Se incluyen también aquí a aquellos individuos que tienen 
reparos hacia la sociabilidad y que terminan adaptándose con mayor agrado a las condiciones de "trabajador solitario".

c. Los que sufren ostracismo por fricción social provocada por su personalidad: existiría en ciertos individuos una actitud personal o sesgo psicológico de resistencia (la víctima propiciatoria) por el cual poco a poco se van generando las condiciones para que el grupo termine aplicándole "el trato silencioso". Según Longzeng et al. (2011), existen ciertos individuos que presentan características personales que inducen al ostracismo por parte de su grupo. Es el caso de los "desagradables" (para un cierto consenso grupal), introvertidos y neuróticos. No se pretende aquí rotular como culpable al individuo sometido a ostracismo, sino señalar que existen ciertos perfiles psicológicos que operan como inductores al exilio de las víctimas propiciatorias, que con su accionar van creando las condiciones para que el grupo los destierre de una forma consciente o no.

Como una forma de resumir la tipología descripta para el ostracismo, se señala que existirían tres tipos distintos, a saber: el originado en el juego político de la organizaciones; el causado en ciertas características del trabajo que aíslan socialmente al individuo; y el originado en un tipo de personalidad, perfil o psicosis que es considerado "indeseable o desagradable" por un grupo dominante.

Girard (2006) señala, que cuando las comunidades entran en crisis se vuelven violentas y expulsan a los individuos que las desafían y que provocan o representan ese "desorden". Sostiene que la cohesión de una sociedad necesita generar a veces víctimas propiciatorias o chivos expiatorios para generar ese orden. Sacrificar a algún individuo es mejor que enfrentar un conflicto generalizado. Por ello, se entiende que el ostracismo como forma de castigo organizacional, es relevante frente a un escenario de grandes cambios.

\section{Las etapas por las que pasa un ostracismo}

A continuación se describirán las etapas por las cuales pasa una víctima de ostracismo. Esta secuencia es una elaboración propia en base a los textos de Eisenberg et al. (2003), Zadro, Williams y Richardson (2004), Van Beest y Williams (2006), Williams (2007 a, 2007 b) y Schechtman (2008) quienes inicialmente reconocen tres etapas: la reflexiva, la reflectiva y la resignación. Según la evidencia acumulada y la experiencia de los autores del artículo, habría que sumar una etapa adicional que es la sorpresa. A continuación se detallan las etapas:

a. Etapa de sorpresa o extrañeza: el individuo sometido a ostracismo comienza a darse cuenta de su situación de aislamiento e invisibilidad. La velocidad de la constatación varía según cada personalidad. La primera reacción es de asombro frente a la anormalidad que descubre en su relación con los demás o con el trato por debajo de lo usual que se le brindaba.

b. La etapa reflexiva: aquí el individuo experimenta un sentimiento de dolor, de angustia o desamparo frente a la situación de aislamiento. Según Wi- 
Iliams (2007 a, 2007 b) es en esta etapa en la que se registran variaciones (descensos) en cuatro dimensiones de la personalidad, a saber: autoestima (valoración de uno mismo), sentido de pertenencia (grupo al cual el individuo referencia como propio), control (el individuo necesita un nivel de control mínimo sobre su medioambiente social, por ejemplo, comunicarse, saludar, intercambiar, entre otras.) y sentido de la existencia (el individuo necesita tener un cierto sentido o visión para su ser). Aquí es donde el individuo experimenta un gran estrés ${ }^{5}$.

c. La etapa reflectiva: aquí el individuo desarrolla alguna estrategia frente a la situación de aislamiento, de rechazo social. Las reacciones son variadas pero las alternativas son dos: luchar por reintegrarse o intentar restituir la situación al estado anterior -mostrando docilidad o aceptando los correctivos-, o combatir la situación de invisibilidad mediante el conflicto abierto con el grupo dominante. En esta etapa se registran diversas sensaciones o respuestas como ser; cierta agresividad, hostilidad, ansiedad, incertidumbre, extrema sensibilización respecto de su medio social, susceptibilidad, sensación de rechazo, agotamiento emocional, entre otras.
También aquí se producen incrementos en el celo profesional, dado que el individuo reclama permanentemente el respeto del grupo dominante a sus áreas o saberes específicos de incumbencia profesional, organizacional, laboral o familiar.

d. Etapa de la resignación, huida o explosión: aquí se observa el desenlace de la situación de rechazo social. Luego de haber intentado reintegrarse o combatir al grupo, el individuo puede adoptar varias posturas, a saber: la resignación o aceptación, por la cual la víctima al haber fracasado en su estrategia de reinserción o de conflicto, termina admitiendo como inmodificables las adversidades de su situación de aislamiento. Puede existir aquí una sensación de autoinculpación o la percepción de haber sido derrotado por el grupo dominante y sometido a la condición de paria. Las depresiones pueden acompañar esta etapa. La segunda alternativa posible aquí, es la huida. El individuo decide abandonar la organización o el medio que lo somete al rechazo social, mediante un cambio de lugar (mudanza o emigración) o mediante un conflicto final, a través de la cual y en un hecho de alta violencia intenta poner fin a la situación (suicidio, agresiones físicas a sus compañeros de

5 Williams (2007 a, b) señala que a nivel físico, los individuos sometidos al experimento del ostracismo, evidencian incrementos en el nivel de la presión arterial y del cortisol (hormona que en niveles excesivos, provoca desórdenes en los sistemas circulatorio, digestivo y respiratorio). Cuanto mayor sea el tiempo de exposición de un individuo a este tipo de situaciones, mayores son las probabilidades de provocarle daños físicos. 
trabajo o familiares, venganzas ejemplificadoras a sus victimarios, entre otros).

Para concluir este punto, se puede señalar, que los ostracismos de corto y largo plazo, tienen respuestas distintas por parte de los "aislados". Si la situación de ostracismo es de corta duración, las respuestas de las víctimas suelen ser menos dramáticas que si es de largo plazo. Una perspectiva de castigo o aislamiento de gran extensión temporal (vivir rechazado por el resto de su vida, caer en la categoría de paria permanente, la muerte civil, etc.) lleva a que los individuos tengan respuestas más violentas (Williams, 2007 a, 2007 b; Baumeister et al., 2002; Macdonald y Leary, 2005; Zadro et al., 2004).

\section{Efectos del ostracismo sobre las víctimas y el grupo victimario}

A pesar de haber tratado en secciones previas este tópico, el ostracismo tiene sobre el individuo efectos negativos: provoca ansiedad, depresión, caída en el nivel de autoestima, sensación de descontrol sobre su medio social, sentido de inutilidad existencial, agresividad, violencia, entre otros. También tiene impactos físicos sobre la víctima a nivel del incremento de la presión arterial y diversas alteraciones del sistema digestivo, circulatorio y respiratorio (Williams, 2001; Lustenberg y Williams, 2008; Zadro et al., 2004).

Si bien, el ostracismo tiene efectos fuertemente negativos sobre las víctimas, para los grupos dominantes los resultados son positivos desde el punto de vista de su cohesión e integración. Los grupos que aplican ostracismo a algún "caso desviado" incrementan su sentido de unión y refuerzan su identidad. El castigo no solo tiene un afán correctivo sobre la víctima sino que posee también un efecto ejemplificador para el grupo dominante. La ejemplaridad o racionalidad del castigo tiene un destinatario más grande que el transgresor: el grupo social (Foucault, 1976; Gruter y Masters, 1986).

En relación a los efectos positivos en aquellas personas que sufrieron un ostracismo y fueron "resocializados", se muestran más solidarios, más atentos al cambio de clima del grupo e incrementan su susceptibilidad social. Pero se debe admitir que la situación de estrés que vivió tiene alguna consecuencia perdurable sobre su comportamiento (Williams, 2001; Lustenberg y Williams, 2008).

El uso del "tratamiento silencioso" en diversas organizaciones, es un hecho que está generalizado y no tiene tanta condena social como las situaciones de violencia explícita contra los "transgresores" (Zadro et al., 2006). Para Williams (2001; 2007 a, 2007 b) el ostracismo es una forma de violencia social que mostraría un cierto grado de avance respecto de las situaciones primitivas en las cuales se sometía a la muerte o desaparición física a las personas que transgredieran las normas del grupo.

\section{Conclusiones}

En este artículo se realizó una breve genealogía del ostracismo como forma de castigo de las organizaciones sociales. Se mostró que en sus orígenes en la Grecia clásica del 500 a. de C., se lo 
creó con la finalidad cívica de prevenir las dictaduras. Luego por una cuestión de la dinámica del juego político, se lo transformó en un mecanismo de control y ajuste del conflicto entre facciones rivales en la naciente democracia ateniense.

En la tradición judeo-cristiana, (aportado por el helenismo de Alejandro Magno en el 300 a. de C.) se lo incorporó como una herramienta de control religioso mediante la cual se pretendía corregir o castigar a los casos de individuos desviados de una cierta "normalidad" de su fe. De la religión luego vuelve a la política, cuando el cristianismo cobra carácter de "religión oficial" en muchas regiones de occidente.

El ostracismo como práctica social es relativamente común en las sociedades contemporáneas. Con la revolución tecnológica de las comunicaciones y las redes sociales no cambió en su naturaleza, sino en su alcance. La víctima del tratamiento silencioso ya no tiene que estar "cerca" el grupo. Como herramienta social, tiene efectos disciplinantes y también adversos (físicos y psicológicos) sobre la víctima y de una mayor cohesión para el grupo que lo ejerce.

En relación a la tipología del "tratamiento silencioso" y al proceso o secuencia que puede seguir, se entiende que existe aún un largo camino para recorrer, en el sentido de una mayor comprobación empírica de los tipos y las etapas. Pero debe reconocerse que contar con algunos elementos claros para explorar dicho campo, es sin duda, un avance para ser tenido en cuenta.

Debe suponerse entonces que, si bien el ostracismo no es un concepto nuevo en la teoría de las organizaciones ni en las ciencias sociales contemporáneas, ha cambiado la mirada que se tiene del fenómeno. El cambio tecnológico y su relación con las formas de violencia organizacional como el tratamiento silencioso, el acoso moral y laboral, entre otros, han atraído una mayor atención de los académicos y de las opiniones públicas, tanto para comprender en profundidad al fenómeno como para instrumentalizarlo con algún cuestionable propósito práctico en las organizaciones.

Basado en el análisis bibliográfico y el desarrollo de ésta investigación empírica respecto del tema, se observa que ciertas organizaciones utilizan al ostracismo como una forma de obtener mayor cohesión del grupo dominante así como también infundirle a la víctima ocasional una mayor sensibilidad respecto de las demandas y normas formales e informales vigentes. Estas prácticas son fuertemente criticables -tanto desde el punto de vista ético como prácticopues el artículo evidencia que todo ostracismo tiene algún efecto negativo psíquico y físico en las víctimas.

En relación al clima organizacional que se vive en un caso concreto de ostracismo, se señala que el grupo dominante puede percibirlo como positivo, dado que toda afirmación de identidad y cohesión grupal provocaría una sensación de mayor bienestar. A contrario sensu, el clima es absolutamente negativo para la víctima del ostracismo. Si por el bienestar relativo de un grupo dominante se debe pagar el alto precio del sufrimiento de "algunos" individuos, se evidenciaría que ciertas organizaciones se alejan por completo de visiones humanitarias y enaltecedoras del ser humano, transformándolas en una prisión física o psíquica. 
En suma, el aprendizaje humano más estable y duradero se logra por el convencimiento de los individuos antes que por el temor o la retribución monetaria.

\section{Referencias Bibliográficas}

Aglamisis; Jorgelina (2011). El maltrato laboral: una perspectiva organizacional en Violencia, maltrato, acoso laboral. El mobbing como concepto, Viviana Vega, coordinadora. Buenos Aires: Lugar Editorial.

Baumeister, Roy F., Twenge, Jean M. y Nuss, Christopher K. (2002). Effects of social exclusion on cognitive process. Anticipated aloneness reduces inteligent thought. Journal of Personality and Social Psychology, 83, 817827.

Creswell, John W. (1998). Qualitative inquiry and research design; choosing among five traditions; Thousand Oaks, USA, SAGE Publications.

Crothers, Laura M. y Levinson, Edward M. (2004). Assessment of bullying: a review of methods and instruments. Journal of Counselling y Development, 82 (4), 496-503.

Davenport, Noa Z.; Schwartz, Ruth D., y Elliott, Gail P. (2005). Mobbing: emotional abuse in the American workplace. Ames, Indiana, USA: Civil Society Publishing.

De La Garza, Mercedes y Valdés, María Del Carmen (1998). Teoría e Historia de las religiones. México, DF., México: Facultad de Filosofia y Letras UNAM.

Eban, Abba S. (1968). Mi pueblo: la historia de los judíos. Ed. Milá, Buenos Aires, Argentina.

Einarsen, Stale, Hoel, Helge, Zapf, Dieter, y Cooper, Cary L. (2003). Bullying and emotional abuse in the workplace. International perspectives in re- search and practice. London, UK: Taylor y Francis.

Eisenberg, Naomi I., Lieberman, Matthew D., y Williams, Kipling D. (2003). Does rejection hurt? An FMRI study of social exclusion. Science (302), 290-292.

El Mundo (2012) en: http://www.elmundo.es/ elmundo/2012/07/05/economia/1341 473311.html

Eliade, Mircea (1961). Traité d'Histoire des Réligions. Paris, France: Ed. Payot.

Fassio, Adriana (2011). Los profesionales de edad avanzada en la Administración Pública y su continuidad laboral más allá de la edad. Universidad De Buenos Aires, Facultad de Ciencias Económicas. Buenos Aires: FCE-UBA.

Forgas, Joseph, Von Hippel, William y Williams, Kipling D. (2005). The Social Outcast: Ostracism, Social Exclusion, Rejection, and Bullying. New York, USA: The Psychology Press.

Foucault, Michel (1976). Vigilar y castigar: el nacimiento de la prisión. Buenos Aires, Argentina: Siglo XXI.

Girard, René (2006). Aquel por el que llega el escándalo. Madrid, España: Editorial Caparrós.

Gruter, Margaret y Masters, Roger D. (1986). Ostracism as a social and biological phenomenon: an introduction. Journal of Ethology and Sociobiology (7), 149-158.

Hecker, Thomas E. (2007). Workplace Mobbing: a discussion for librarians. Journal of Academic Librarianship, 33 (4), 439-445.

Kagan, Donald (1961). The origin and purpose of ostracism. Hesperia: The journal of the America $\mathrm{n}$ School fo Classical Studies at Athens, 30 (4), 393-401.

Kitto, Humphrey D. F. (1977). Los griegos. Buenos Aires, Argentina: Eudeba.

Lederman, Michelle Tillis (2012). The 11 laws of likability. New York, USA: Amacom. 
Longzeng, Wu; Liquin, Wei; y Hui, Chun (2011). Dispositional antecedents and consequences of workplace ostracism: an empirical examination. Front Bus. Res. China, 5 (1), 23-44.

Lustenberg, Donald E., y Williams, Kipling D. (2008). Ostracism in organizations. En Greenberg, Jerald y Edwards Marissa S., Voice and silence in organizations. New York, USA: Emerald Group Publishing Limited.

Macdonald, Geoff y Leary, Mark R. (2005). Why does social exclusion hurts? The relationship between social an physical pain. Psychological Bulletin, 131 (2), 202-223.

Morgan, Gareth (1997). Images of organization, Thousand Oaks, USA: Sage Publications.

Piñuel, Iñaki (2008). Mobbing, el estado de la cuestión. Madrid, España: Gestión 2000.

Platon (2007). Apología de Sócrates. Buenos Aires, Argentina: Gradifico Editores.

Robson, Colin (2002). Real world research, Melbourne, Australia. Blackwell Publishing

Schechtman, Gregory M. (2008). When silence speaks louder than words: computer mediated communicatios and perceived ostracism. Washington State University, Department of Bussiness. Washington: $\mathrm{Ph}$. D. dissertation.

Serlin, José (2000). Conocimiento de la gestión de las organizaciones: sistemas complejos dinámicos inestables adaptativos. Buenos Aires: FCE-UBA.

Stake; Robert (2010) Qualitative research: studying how things work; New York, USA, Guilford Press.

Van Beest, Ilja, y Williams, Kipling D. (2006). When inclusion costs and ostracism pays, ostracism still hurts. Journal of Personality and Social Psychology, 91 (5), 918-928.

Westhues, Kenneth (2003). A summary of research on workplace mobbing. (Universtity of Waterloo, Ed.) Canada's occupational health y safety magazine, 18, 30-36.

Whitted, Kathryn S., y Dupper, David R. (2005). Best practices for preventing or reducing bullying in schools. Children and Schools, 27 (3), 167-175.

Williams, Kipling D. (2001). Ostracism: the power of silence. New York, New York, USA: Guilford Press.

Williams, Kipling D. (2007a). Ostracism. Annual Review of Psychology, 58, 425-452.

Williams, Kipling D. (2007b). Ostracism: the kiss of social death. Social and Personality Psychology Compass, 1 (1), 236-247.

Yin, Robert (1994) Case study research; design and methods; Thousand Oaks, USA, SAGE Publications.

Zadro, Lisa; Williams, Kipling D.; y Richardson, Robert (2004). How low can you go? Ostracism by a computer is sufficient to lower self-reported levels of belonging, control, self-esteem and meaningful existence. Journal of Experimental Social Psychology (40), 560-567.

Zadro, Lisa; Boland, John C., y Richardson, Robert (2006). How long does it last? The persistence of the effects of ostracism in the socially anxious. Journal of Experimental Social Psychology, 42 (5), 692-697.

Zimmerle, Howard (2012). Co-worker ostracism an shunning as retaliation under the Title VII. University of lowa, College of Law, Des Moines-lowa. 